\title{
Emotional reactions to infidelity
}

\author{
Todd K. Shackelford, Gregory J. LeBlanc, and Elizabeth Drass \\ Florida Atlantic University, Davie, USA
}

\begin{abstract}
We sought to identify emotional reactions to a partner's sexual infidelity and emotional infidelity. In a preliminary study, 53 participants nominated emotional reactions to a partner's sexual and emotional infidelity. In a second study, 655 participants rated each emotion for how likely it was to occur following sexual and emotional infidelity. Principal components analysis revealed 15 emotion components, including Hostile/Vengeful, Depressed, and Sexually aroused. We conducted repeated measures analyses of variance on the 15 components, with participant sex as the between-subjects factor and infidelity type as the withinsubjects factor. A main effect for sex obtained for 9 components. For example, men scored higher on Homicidal/Suicidal, whereas women scored higher on Undesirable/Insecure. A main effect for infidelity type obtained for 12 components. For example, participants endorsed Nauseated/Repulsed as more likely to follow sexual infidelity and Undesirable/Insecure as more likely to follow emotional infidelity. Discussion addresses limitations of this research, and highlights the need for an integrative theory of emotional reactions to infidelity.
\end{abstract}

Marriage occurs in every known culture (Brown, 1991; Epstein \& Guttman, 1984; Vandenberg, 1972). So, too, does infidelity. Estimates of infidelity among American married couples range from $26 \%$ to $75 \%$ (Buss, 1994; Hite, 1987; Kinsey, Pomeroy, \& Martin, 1948; Kinsey, Pomeroy, Martin, \& Kebhard, 1953). Infidelity is not confined to American or even to Western marriages. In a study of 160 cultures, infidelity was the most frequently cited reason for divorce (Betzig, 1989).

Infidelity can have destructive consequences. Suspicion of a partner's infidelity elicits jealousy in men and in women (Buss \& Shackelford, 1997; Daly \& Wilson, 1988). Sexual jealousy can have particularly disastrous consequences when elicited in men. The most frequent cause of wife-battering

Please send correspondence and requests for reprints to Todd K. Shackelford, Florida Atlantic University, Division of Science-Psychology, 2912 College Avenue, Davie, Florida 33314, USA; e-mail: tshackel@fau.edu.

The authors thank April Bleske, David Buss, Martie Haselton, Dennis Ward, and Viviana Weekes-Shackelford for helpful discussions of this research. 
and wife-killing is male sexual jealousy (Daly, Wilson, \& Weghorst, 1982; Wilson \& Daly, 1992). Male sexual jealousy also is the cause of many husband-killings. In a sample of 47 murders precipitated by a jealous man, nine of the murdered were men killed in self-defence by women accused of infidelity (Daly et al., 1982).

Infidelity is a significant theoretical issue. From an evolutionary perspective (Buss, Larsen, Westen, \& Semmelroth, 1992; Buss \& Shackelford, 1997), infidelity signals the diversion of important reproductive resources. From an equity perspective (Walster, Walster, \& Perscheid, 1978), infidelity signals inequities in a relationship. From an investment model perspective (Rusbult, 1980), infidelity signals lack of commitment to a relationship. In short, infidelity acquires importance in any theory of romantic relationships.

Previous work, much of it guided by an evolutionary psychological perspective, documents large sex differences in emotional reactions to a partner's infidelity, across many different cultures and using different methodologies (e.g., Buunk, Angleitner, Oubaid, \& Buss, 1996; Buss et al., 1992; Buss et al., 1999; de Weerth \& Kalma, 1993; Geary, Rumsey, BowThomas, \& Hoard, 1995; Wiederman \& Allgeier, 1993). Men, more than women, display greater upset in response to a partner's sexual infidelity, whereas women, more than men, display greater upset in response to a partner's emotional infidelity. Sexual infidelity refers to sexual activity with someone other than one's long-term partner. Emotional infidelity occurs when one's partner channels resources such as romantic love, time, and attention to someone else. Researchers working from other theoretical perspectives, including social role theory and socialisation-based models, also have documented these sex differences in emotional reactions to infidelity (e.g., DeSteno \& Salovey, 1996; Hupka \& Bank, 1996).

An important empirical and theoretical question is: What specific emotions occur in reaction to a partner's infidelity? Much research has assessed the emotion of jealousy (see Salovey, 1991; White \& Mullen, 1989). Recent research suggests, however, that jealousy is not a single emotion but instead includes many component emotions (e.g., Bryson, 1991; Sharpsteen, 1993; Sharpsteen \& Kirkpatrick, 1997; Zammuner, 1995; Zammuner \& Fischer, 1995; Zammuner \& Frijda, 1994). Perhaps the most exhaustive previous attempt to identify empirically the component emotions of jealousy was conducted by Sharpsteen (1993). Sharpsteen conducted a prototype analysis of "romantic jealousy", whereby he asked participants to list "the characteristics of romantic jealousy (e.g., what people think, feel, or do when jealous; the circumstances under which it would occur)" (p.72). Sharpsteen identified 86 emotions, thoughts, and actions associated with romantic jealousy.

Two important differences exist between Sharpsteen's study and the present research. First, whereas Sharpsteen's study was designed to identify the 
component features of romantic jealousy, the present studies are designed to identify the emotional reactions to a partner's infidelity. Not once in the instructions to participants in the present work is the term "jealousy" used. The use of "jealousy" is avoided to allow participants to generate a wide array of emotions, including emotions not usually associated with jealousy, such as happiness and relief.

A second difference between Sharpsteen's study and the present studies is that Sharpsteen's study sought to identify the emotions, cognitions, and behaviours associated with romantic jealousy, whereas the present studies seek to identify only the emotional reactions to a partner's infidelity. In follow-up work, Sharpsteen and Kirkpatrick (1997) cluster analysed the 86 emotions, cognitions, and behaviours and identified 17 clusters of features, including Vengefulness, Sadness, and Fear. The present research provides an opportunity to examine whether Sharpsteen and Kirkpatrick's (1997) clusters can be replicated, using a different methodology. In a preliminary study, we use an act nomination method (Buss \& Craik, 1983) to identify the range and diversity of participant-generated emotional reactions to a partner's infidelity. In the primary study, we identify the components underlying these emotions.

We located one previous study that went beyond a request for rating or selecting a single emotional reaction to a partner's infidelity, where the two types of infidelity were differentiated and where the responses of men and women were differentiated. Geary et al. (1995) asked Chinese and American men and women to rate how hurt, jealous, and angry they would feel on discovering a partner's sexual infidelity or emotional infidelity. When imagining a partner's sexual or emotional infidelity, no sex differences were detected for the full sample (Chinese and American participants) for hurt, jealousy, or anger. However, for the American sample alone, women reported greater hurt, jealousy, and anger. These sex differences were replicated by Geary et al. in a second study. Conflicting results were obtained for the Chinese sample: In the first study, no sex differences were detected in ratings for hurt, jealousy, or anger in reaction to a partner's sexual infidelity. In a second study, however, Chinese men scored higher than Chinese women on all three emotions. The present research in part allows for a replication and extension of the Geary et al. (1995) results, using a different methodology.

In summary, the goal of the present research is to identify a wide range of participant-generated emotional reactions to a partner's infidelity, while at the same time differentiating: (a) the reactions of men from the reactions of women, and (b) the reactions to a partner's sexual infidelity from the reactions to a partner's emotional infidelity. In a preliminary study, participants nominated emotional reactions to a partner's sexual and emotional infidelity. A new group of participants rated each emotion for how likely it was to occur following sexual and emotional infidelity. 


\section{METHODS}

\section{Preliminary study}

We used an act nomination method to identify the range and diversity of emotional reactions to a partner's sexual infidelity and emotional infidelity (Buss \& Craik, 1983). A total of 53 undergraduates (34 women, 19 men; 80\% Caucasian; mean age 19 years) were instructed to think of a past, future, or their current committed, sexual relationship. Each participant completed two forms. The instructions for the form assessing emotional reactions to sexual infidelity were: "Imagine that you find out that your partner has been having sex with someone else. Imagine your partner trying-and enjoying-many different sexual positions and activities with this other person. Imagine that most of your partner's waking thoughts and fantasies are about having sex with this other person". The instructions for the form assessing emotional reactions to emotional infidelity were: "Imagine that you find out that your partner has fallen in love with another person. Your partner has become deeply emotionally attached to this other person, and thoughts of this other person consume your partner's every thought',. Participants were instructed to write on the lines provided 15 emotions they might feel in reaction to each type of infidelity.

The emotional reactions nominated by men and women overlapped substantially, as did the emotions nominated as reactions to sexual infidelity and emotional infidelity. Thus, we created a single list of emotions that included the emotional reactions nominated by men and women for sexual and emotional infidelity. After assembling the list of emotions, we eliminated redundancies. This elimination process erred toward overinclusion in that emotions with even partial distinctiveness (e.g., "nauseated" and "sickened") were retained to maximise the range of coverage. We eliminated words or phrases that clearly were not emotions, such as "I would kill her if she cheated on me". This elimination process also erred toward overinclusion, and we retained any term that might be construed as an emotion or affect, such as "homicidal", "sexually aroused", and "blameworthy'. We appreciate that some might disagree that these are emotions, but we retained them in an effort to create a list of descriptors that would capture the full range of possible emotional reactions to a partner's infidelity.

Also in an effort to cover of the full range of emotions, we consulted Russell's (1980) circumplex model of affect. Russell identified 28 emotion terms that tap eight dimensions of affect. When organised as a circumplex model, these eight dimensions fully cover the range of affect. Three of Russell's affect dimensions were not well represented among the emotional reactions to infidelity nominated by participants: Pleasure, Sleepiness, and Contentment. We added to participants' nominations affect terms from these three dimensions. The final list comprised 103 emotional reactions to infidelity. Sample emotions are: undesirable, vengeful, sad, helpless, happy, shocked, nauseated, blame- 
worthy, relieved, humiliated, sexually aroused, sleepy, homicidal, anxious, and forgiving.

\section{Primary study}

The first goal of the primary study was to identify the component structure of the 103 emotional reactions to infidelity. Assuming an interpretable structure emerged, and based on previous theoretical and empirical work, we wanted to investigate: (a) sex differences in emotional reactions to a partner's infidelity, (b) differences in emotional reactions to a partner's sexual infidelity versus a partner's emotional infidelity, and (c) whether the sex differences in emotional reactions depend on infidelity type.

Participants. These were 655 students (324 males, 331 females) drawn from a departmental participant pool at a university in the Southwest. Participants received credit toward their grade in an introductory psychology course. About 59\% of participants were Caucasian, 19\% Hispanic, 17\% Asian American, and 5\% African American. The mean age of participants was 19.4 years, ranging from 17 to 40 years. About $90 \%$ of participants reported past or current involvement in a committed romantic relationship. About $75 \%$ of these relationships included sexual intercourse. About $65 \%$ of participants reported that they had had sex with someone else, fallen in love with someone else, or both while involved in a committed relationship. About $80 \%$ of participants suspected or knew that their partner in a committed relationship had had sex with someone else, fallen in love with someone else, or both while involved with the participant.

Materials and procedures. The survey completed by participants opened with several biographical questions, followed by a section on romantic relationship history. Next, participants were instructed to think about a past, future, or their current committed, sexual, romantic relationship, and to imagine that their partner has been unfaithful. Participants were instructed to indicate for each of 103 emotions the degree to which they would feel that emotion if their partner was: (a) sexually unfaithful but not emotionally unfaithful, and (b) emotionally unfaithful but not sexually unfaithful. Ratings were provided on a 9point scale ranging from 0 ("I would not experience this emotion at all" to 8 ("I would be consumed with this emotion"').

To the left of each emotion were two blank spaces, forming two columns of blank spaces down the left side of the page. At the top of each column was the label "Emotionally unfaithful, but NOT sexually unfaithful" or "Sexually unfaithful, but NOT emotionally unfaithful". We reversed the order of the columns for half the surveys. The 103 emotions were presented in a single, random order. In sum, the primary study was a 2 (participant sex) $\times 2$ (infidelity 
type) design, with participant sex a between-subjects variable and infidelity type a within-subjects variable. About 30 students of the same sex participated in each session.

\section{RESULTS}

To identify the most general component structure that might underlie the 103 emotions, we performed a principal-components analysis followed by varimax rotation on the ratings, collapsing across participant sex and infidelity type. Although 21 components emerged with eigenvalues greater than 1.0, the varimax solution failed to converge for this large number of components. We examined several principal components solutions in which we extracted and rotated a varying number of components. An interpretable solution emerged when we extracted and rotated 15 components that accounted for $60 \%$ of the variance in ratings. The initial scree plot showed a substantial decline in the slope of the plot after the 15 th component, corroborating the decision to retain 15 components based on interpretability.

Table 1 displays the 15 components and the emotions loading at least I. 30 I on each component but not loading greater than $|.30|$ on any other component. The components are presented in order of variance accounted for, beginning with

TABLE 1

Loadings for 15 components of emotional reactions to infidelity

\begin{tabular}{lclc}
\hline Components and emotions & Loading & Components and emotions & Loading \\
\hline Undesirable/Insecure & & Hostile/Vengeful & \\
$\quad$ Undesirable & .81 & Hostile & .76 \\
Physically unattractive & .79 & Enraged & .74 \\
Insecure & .73 & Vengeful & .74 \\
Self-conscious & .71 & Spiteful & .73 \\
Inferior & .70 & Angry & .71 \\
Unwanted & .70 & Outraged & .69 \\
Unimportant & .66 & Bitter & .66 \\
Worthless & .65 & Aggressive & .65 \\
Inadequate & .63 & Hatred & .65 \\
Inept & .59 & Deceived & .51 \\
Unloved & .55 & Betrayed & .43 \\
Unappreciated & .50 & & \\
Boring & .47 & Depressed & .75 \\
Lonely & .46 & Sad & .65 \\
Jealous & .41 & Depressed & .63 \\
Afraid & .41 & Hurt & .58 \\
Beaten & .40 & Miserable & \\
\hline
\end{tabular}


TABLE 1

(Continued)

\begin{tabular}{|c|c|c|c|}
\hline Components and emotions & Loading & Components and emotions & Loading \\
\hline Heartbroken & .53 & Blameworthy & .68 \\
\hline Weepy & .52 & Responsible & .67 \\
\hline Shattered & .52 & Self-hate & .45 \\
\hline Alone & .50 & Incompetent & .36 \\
\hline Gloomy & .42 & \multicolumn{2}{|l|}{ Content/Relieved } \\
\hline Anguish & .35 & $\begin{array}{l}\text { Content/Relieved } \\
\text { Content }\end{array}$ & .68 \\
\hline Helpless/Abandoned & & Satisfied & .62 \\
\hline Helpless & .69 & Relieved & .62 \\
\hline Distressed & .56 & Serene & .50 \\
\hline Powerless & .55 & At ease & .39 \\
\hline Hopeless & .52 & \multirow{2}{*}{\multicolumn{2}{|c|}{ Humiliated }} \\
\hline Neglected & .48 & & \\
\hline Confused & .48 & Embarrassed & .59 \\
\hline Abandoned & .48 & Humiliated & .55 \\
\hline Empty & $\begin{array}{r}.40 \\
47\end{array}$ & Ashamed & .55 \\
\hline Rejected & & Foolish & .38 \\
\hline $\begin{array}{l}\text { Kejected } \\
\text { Frustrated }\end{array}$ & .45 & Abused & .37 \\
\hline Frustrated & .42 & Disrespected & .33 \\
\hline Annoyed & .35 & Used & .33 \\
\hline Happy & & \multicolumn{2}{|l|}{ Sexually aroused } \\
\hline Pleased & .83 & Aroused & .74 \\
\hline Delighted & .82 & Sexually aroused & .73 \\
\hline Glad & .66 & & \\
\hline Happy & .53 & \multicolumn{2}{|l|}{ Tired } \\
\hline Excited & .46 & Sleepy & .76 \\
\hline Disappointed & -.37 & Tired & .71 \\
\hline & & Bored & .39 \\
\hline $\begin{array}{l}\text { Shocked } \\
\text { Shocked }\end{array}$ & 76 & Droopy & .35 \\
\hline Surprised & .74 & \multicolumn{2}{|l|}{ Homicidal/Suicidal } \\
\hline Astounded & .73 & Homicidal & .54 \\
\hline Disbelief & .67 & Suicidal & .51 \\
\hline Alarmed & .45 & Violent & .33 \\
\hline Nauseated/Repulsed & & \multicolumn{2}{|l|}{ Anxious } \\
\hline Nauseated & .69 & Anxious & .62 \\
\hline Sickened & .58 & Worried & .40 \\
\hline Numb & .55 & Tense & .37 \\
\hline Repulsed & .51 & \multirow{2}{*}{\multicolumn{2}{|c|}{ Forgiving }} \\
\hline Violated & .41 & & \\
\hline Disgusted & 39 & Forgiving & .64 \\
\hline & .39 & Understanding & .50 \\
\hline Blameworthy & & Unforgiving & -.49 \\
\hline Guilty & .73 & & \\
\hline
\end{tabular}

Note: For component solution, $N=655$. Component solution produced by varimax rotation of 15 principal components. 
Undesirable/Insecure, which accounted for the largest percentage of inter-item variance. We conducted additional sets of principal components analyses on emotional reactions to a partner's: (a) emotional infidelity, and (b) sexual infidelity. These analyses (available from the first author on request) also yielded 15 components, virtually identical in content to the 15 components that resulted when the analyses used ratings collapsed across infidelity type.

Undesirable/Insecure includes emotions such as feeling inferior and undesirable that focus on qualities lacking in the participant that the unfaithful partner might be looking for in someone else. Hostile/Vengeful covers the two related dimensions of hostility and vengeance and includes emotions such as enraged and vengeful. Depressed covers a range of depressive emotions, from sad to miserable. Helpless/Abandoned taps feelings of helplessness, as indicated by the high loadings of powerless and hopeless, and feelings of abandonment, as indicated by the high loading of neglected. Happy covers emotions such as delighted and glad. Shock includes emotions such as astounded and alarmed. Nauseated/Repulsed covers symptoms of acute physical illness such as nausea and feeling sickened, but also covers emotions such as feeling repulsed. Blameworthy includes emotions associated with feeling responsible for a partner's infidelity, such as guilty and blameworthy. Content/Relieved differs from the other components in that the emotions included in this component, such as content and serene, are relatively positive or neutral. Humiliated includes emotions such as embarrassed and foolish. Sexually aroused includes just two emotions, aroused and sexually aroused. Tired taps an emotional-physical state that includes items such as sleepy, bored, and droopy. Homicidal/Suicidal includes "violent" and illustrates that emotional reactions to infidelity can motivate destructive behaviours. Anxious covers emotions that tap anxiety, including feeling tense and worried. Forgiving indexes the understanding and forgiveness one has for a partner's infidelity.

To obtain reliable indexes of each component, we summed with unit weighting emotions loading at least $\mid .30 \mathrm{I}$ on the component and not loading greater than $\mid .30 \mathrm{I}$ on any other component. Table 2 shows the number of emotions, reliability coefficients, and mean inter-item correlations for each component for sexual infidelity, emotional infidelity, and across infidelity type. Across infidelity type and separately for sexual infidelity and emotional infidelity, all components show fair to excellent reliability and moderate mean inter-item correlations. All subsequent discussion of the 15 components of emotional reactions refers to the components as presented in Table 2.

For reportorial completeness, Table 3 provides the across-sex correlations among the 15 components. The correlations range from -.51 , between Forgiving and Hostile/Vengeful, to .72, between Helpless/Abandoned and Undesirable/Insecure. Although most of the correlations are positive, ratings for three components correlate negatively with most of the remaining components, but positively among themselves. These components are Happy, Content/ 
TABLE 2

Alpha reliabilities and mean inter-item correlations for 15 components of emotional reactions to infidelity

\begin{tabular}{|c|c|c|c|c|c|c|c|}
\hline \multirow[b]{3}{*}{ Component } & \multirow{3}{*}{$\begin{array}{c}\text { No. of } \\
\text { emotions }\end{array}$} & \multicolumn{4}{|c|}{ Infidelity Type } & & \\
\hline & & \multicolumn{2}{|c|}{ Sexual } & \multicolumn{2}{|c|}{ Emotional } & \multicolumn{2}{|c|}{ Across infidelity type } \\
\hline & & Alpha & IIC & Alpha & IIC & Alpha & IIC \\
\hline Undesirable/Insecure & 17 & .92 & .40 & .92 & .40 & .93 & .43 \\
\hline Hostile/Vengeful & 11 & .91 & .47 & .91 & .47 & .91 & .49 \\
\hline Depressed & 10 & .91 & .51 & .91 & .50 & .91 & .52 \\
\hline Helpless/Abandoned & 11 & .86 & .35 & .85 & .35 & .87 & .37 \\
\hline Нарру & 6 & .73 & .32 & .78 & .37 & .79 & .38 \\
\hline Shocked & 5 & .81 & .46 & .77 & .41 & .80 & .44 \\
\hline Nauseated/Repulsed & 6 & .82 & .43 & .79 & .39 & .82 & .43 \\
\hline Blameworthy & 5 & .82 & .47 & .83 & .49 & .84 & .51 \\
\hline Content/Relieved & 5 & .69 & .31 & .72 & .34 & .72 & .34 \\
\hline Humiliated & 7 & .78 & .33 & .80 & .36 & .80 & .36 \\
\hline Sexually aroused & 2 & .76 & .61 & .59 & .42 & .72 & .56 \\
\hline Tired & 4 & .60 & .27 & .60 & .27 & .61 & .28 \\
\hline Homicidal/Suicidal & 3 & .56 & .30 & .63 & .37 & .62 & .35 \\
\hline Anxious & 3 & .60 & .33 & .63 & .36 & .63 & .37 \\
\hline Forgiving & 3 & .72 & .46 & .69 & .43 & .68 & .41 \\
\hline
\end{tabular}

Note: $N=655 ;$ IIC $=$ mean inter-item correlation.

Relieved, and Forgiving. The pattern of correlations is similar within-sex for males and females (analyses available from the first author on request).

We conducted repeated-measures analyses of variance (ANOVAs) on each emotional reaction component with participant sex as the between-subjects factor and infidelity type as the within-subjects factor. Table 4 presents the results of these tests. Main effects of participant sex on emotional reactions obtained for nine of the 15 components. Men provided higher ratings than women in reaction to a partner's infidelity for Content/Relieved, Homicidal/Suicidal, Happy, and Sexually aroused. Women provided higher ratings than men for Nauseated/ Repulsed, Depressed, Undesirable/Insecure, Helpless/Abandoned, and Anxious.

Main effects of infidelity type on emotional reactions obtained for 12 of the 15 components. Sexual infidelity evoked higher ratings than did emotional infidelity for Hostile/Vengeful, Shocked, Nauseated/Repulsed, Humiliated, Sexually aroused, and Homicidal/Suicidal. Emotional infidelity evoked higher ratings than did sexual infidelity for Undesirable/Insecure, Depressed, Helpless/ Abandoned, Blameworthy, Tired, and Forgiving.

Three of 15 possible interactions between participant sex and infidelity type achieved statistical significance. Women's ratings of Helpless/Abandoned and 


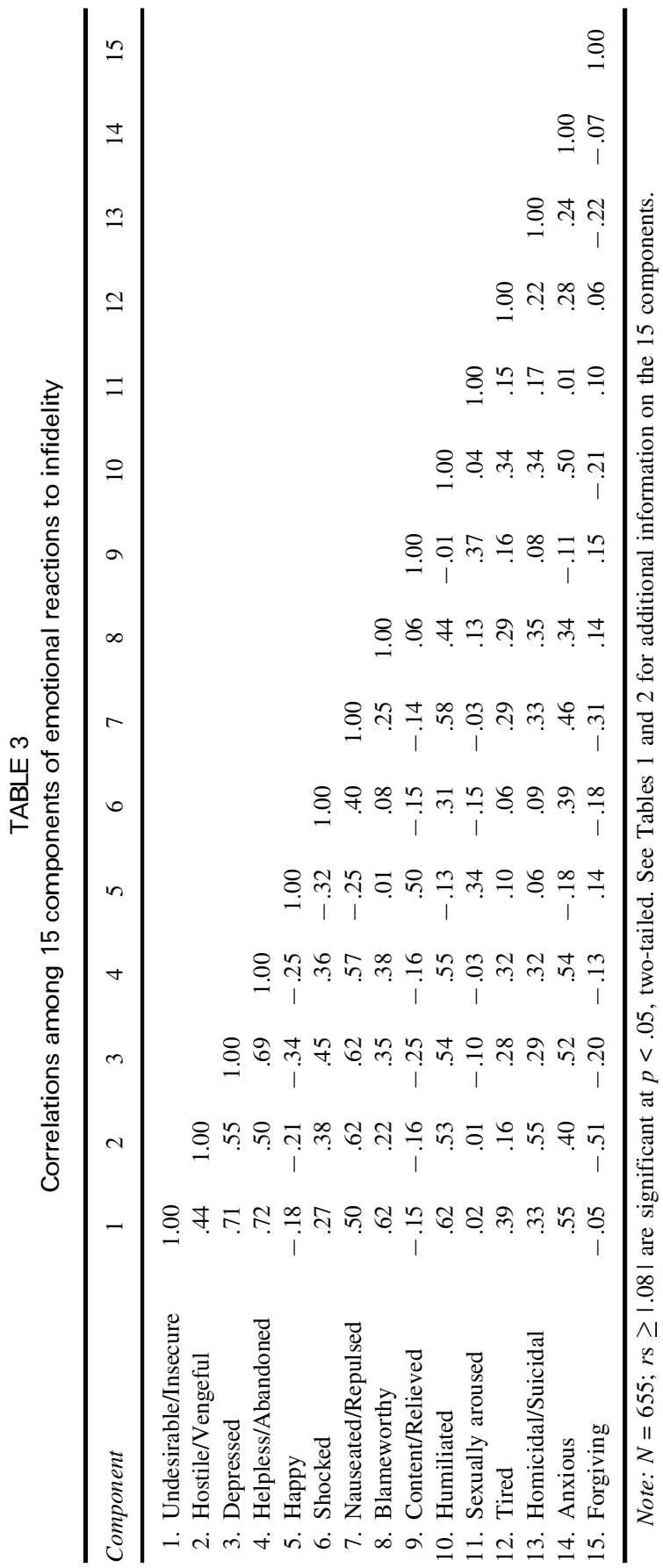




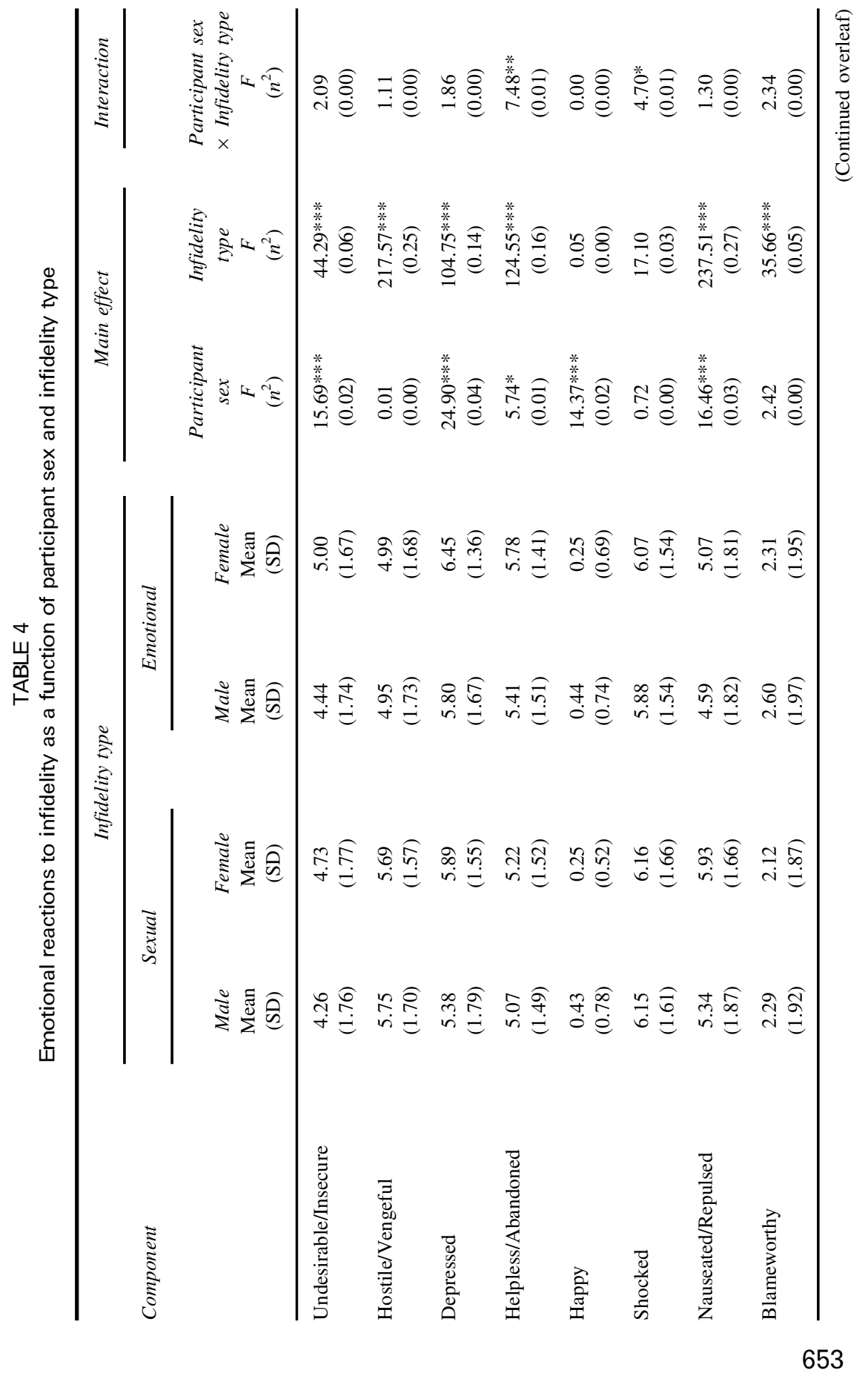




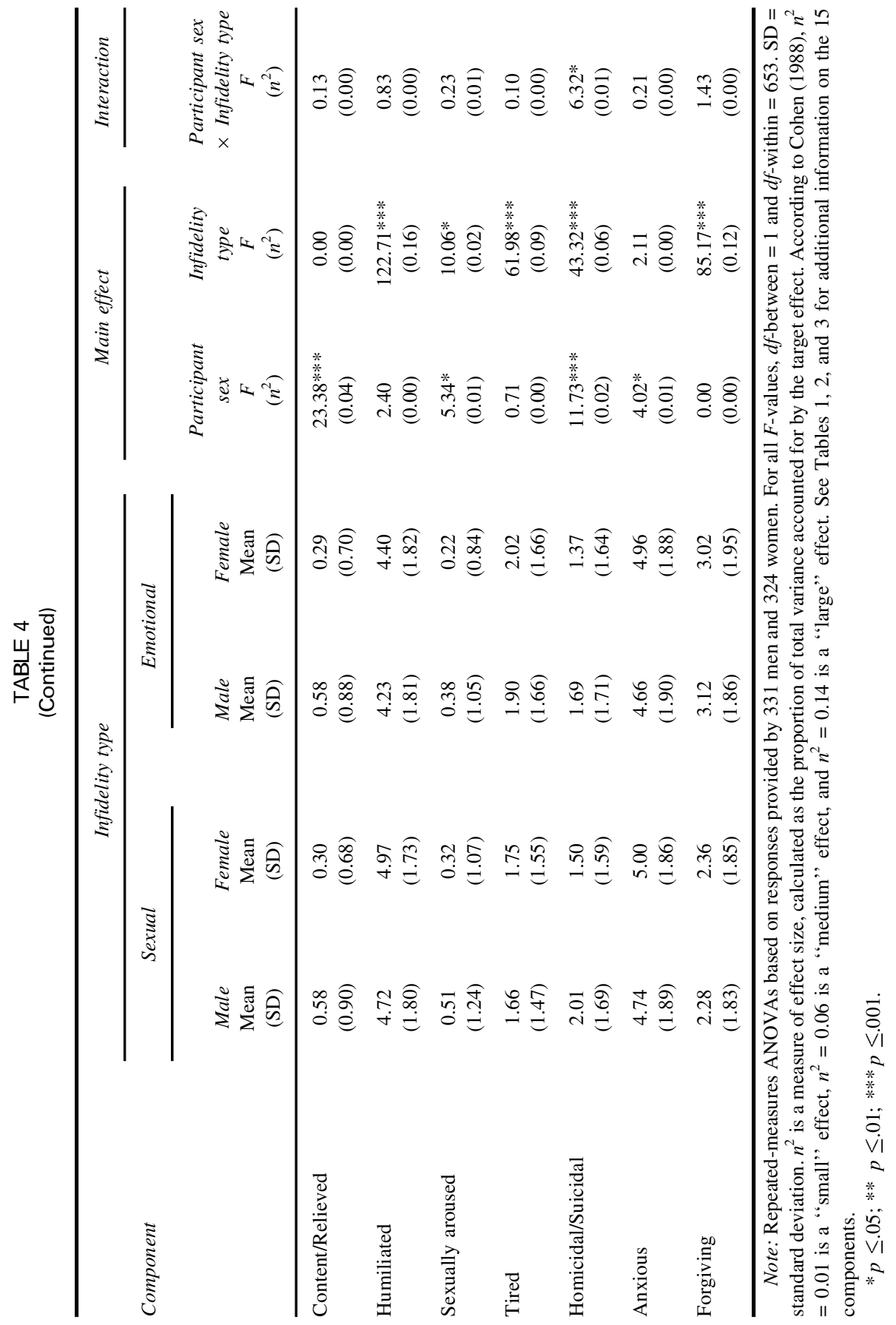


Shocked were higher than men's ratings on these components for both types of infidelity, but the mean sex differences were greater for emotional infidelity than for sexual infidelity. Men's ratings of Homicidal/Suicidal were higher than women's ratings for both types of infidelity, but the mean sex difference was greater for emotional infidelity than for sexual infidelity.

Two sets of follow-up analyses revealed that the sex differences and infidelity type differences were not contingent on experience in a committed relationship or on experience with a partner's infidelity. We conducted repeatedmeasures ANOVAs parallel to the primary analyses, first including only data from participants who had ever been in a committed relationship, and second including only data from participants who indicated that a committed partner had ever been unfaithful. Although the follow-up analyses included data from fewer participants, the results did not differ for either subsample, and they did not differ from the results generated using the full sample of participants (analyses available from the first author on request).

To compare the results for Geary et al.'s (1995) American sample with the results of the present research, we conducted an independent means $t$-test for a sex difference in the ratings for "jealousy', “'angry', and "hurt', In reaction to a partner's sexual infidelity, women report greater anger and hurt ( $M \mathrm{~s}$ for men and women, respectively, for anger: $6.66,7.00$; for hurt: $6.65,7.26$; following are absolute values: $t(653)=2.44, p=.015$, for anger; $t(653)=4.74, p<.001$, for hurt). No sex difference was found for jealousy ( $M$ s for men and women, respectively: $5.55,5.51 ; t=0.21, p>.80$ ). In reaction to a partner's emotional infidelity, women reported greater anger, hurt, and jealousy than men $(M \mathrm{~s}$ for men and women, respectively, for anger: 5.79, 6.15; for hurt: 6.77, 7.43; for jealousy: 5.61, 6.21; following are absolute values: $t(653)=2.19, p=.029$, for anger; $t(653)=5.44, p<.001$, for hurt; $t(653)=3.02, p=.003$, for jealousy).

\section{DISCUSSION}

This research used a novel methodology - the act nomination procedure-to identify a wide range of emotional reactions to a partner's infidelity. A followup study identified 15 components that underlie the 103 participant-nominated emotional reactions. Using these 15 components of emotional reactions, we explored: (a) sex differences in emotional reactions, (b) differences in emotional reactions to a partner's sexual infidelity and emotional infidelity, and (c) interactions between participant sex and infidelity type in emotional reactions to a partner's infidelity.

Many of the components of emotional reactions to infidelity identified in the present research overlap conceptually with the clusters of emotions, cognitions, and behaviours underlying "romantic jealousy" as identified by Sharpsteen and Kirkpatrick (1997). The Hostile/Vengeful component overlaps with Sharpsteen and Kirkpatrick's Irritability, Vengefulness, and Anger clusters. Sharpsteen and 
Kirkpatrick's Sadness cluster maps onto the Depressed components and the Hopeless/Abandoned component. The Inferiority cluster shares conceptual features with the Undesirable/Insecure, Depressed, Helpless/Abandoned, Nauseated/Repulsed, and Anxious components. The Insecurity cluster maps onto the Undesirable/Insecure components. The Future is Not Bright cluster maps onto the Blameworthy and Helpless/Abandoned components, and the Fear cluster maps loosely onto the Shocked component. Sharpsteen and Kirkpatrick (1997) used cluster analysis, whereas in the present research we used principalcomponents analysis. The considerable conceptual overlap between the components identified in the present study and the clusters identified by Sharpsteen and Kirkpatrick (1997) attests to the reliability of the conceptual categories identified in these studies.

The 15 components of emotional reactions identified in the present studies cover the range of affect as presented by Russell (1980), from positive or pleasant (e.g., Happy, Content/Relieved), to negative or unpleasant (e.g., Hostile/Vengeful, Undesirable/Insecure). Although positive or pleasant emotions were not well represented among those listed by participants in the preliminary study, several such emotions were listed. Why did participants in this research nominate positive or pleasant emotions, whereas previous research generated only negative or unpleasant emotions? One possibility is that the wording of the instructions to participants is responsible for the broader nomination of emotional reactions. We asked participants to nominate emotional reactions to infidelity rather than asking participants to nominate emotions (or thoughts or behaviours) associated with "jealousy" or "romantic jealousy". The latter terms have negative or unpleasant connotations for Westerners (see White \& Mullen, 1989), and may elicit a negative or unpleasant mindset. Alternatively, participants nominating emotions such as happy might expect to be delighted to have an excuse to get out of a bad relationship.

Using a different methodology, we replicate two key findings documented by Geary et al. (1995) for their American sample: In reaction to a partner's sexual infidelity, women report greater anger and hurt than do men. In reaction to a partner's emotional infidelity, women report greater anger, hurt, and jealousy than do men. In contrast to the results of Geary et al., however, no sex difference was found for jealousy. It is not clear why the sex difference for jealousy failed to replicate in the current research, especially in the light of the two replications.

The current studies are limited in several ways that suggest directions for future work. One limitation pertains to the samples, who were undergraduates from a single culture and a relatively restricted age range. It is possible that the current studies missed some important emotional reactions that might be more likely to occur in older, married persons, who might be more experienced in the domains of perceiving and committing infidelity. We note, however, that $90 \%$ of participants in the primary study reported past or current involvement in a 
committed relationship. Three in four of these relationships included sexual intercourse. One in five undergraduates reported falling in love with another person while involved in a committed relationship. One in four reported having sex with someone else while involved in a committed relationship. These rates of infidelity are comparable to rates reported for married persons. Thus, the use of undergraduates to identify the emotional reactions to a partner's infidelity is reasonable, although it is important to extend this research to samples of older, married persons.

Another limitation of this research is a methodological limitation. Participants were instructed to imagine their partner's infidelity. We have no reason to expect profound differences in imagined versus actual emotional reactions to a partner's infidelity This is an empirical question, however. Future work can explore, for example, whether the 15 components of emotional reactions identified in this research replicate with reports of emotional reactions to an actual infidelity.

An important direction for future work is to identify the behavioural and cognitive correlates of the emotional reactions to infidelity. A particularly urgent area for research is to examine whether some emotional reactions might signal impending violence against a wife. For example, wife-batterers are reported to experience intense anger and hostility just prior to battering their wives (Daly \& Wilson, 1988). Other attempts to prevent a partner's defection from a relationship_including spousal murder (Buss \& Shackelford, 1997; Daly \& Wilson, 1988; Daly et al., 1982)—also might be predicted by the underlying emotional state of the battering man. If we can predict wife-battery from the emotional state of the batterer, we might be able to intervene and derail an impending disaster.

The present research was not designed to test specific hypotheses derived from a theory of emotional reactions to infidelity. Instead, the overarching goal of this research was to identify a broad array of emotional reactions that people might experience on the discovery of a partner's sexual or emotional infidelity. In addition to identifying 15 component emotional reactions to a partner's infidelity, this research documented that the sexes differ in their experience of some of these emotions. For example, men scored higher on Homicidal/Suicidal, whereas women scored higher on Undesirable/Insecure. This research also documented several differences in the emotional reactions experienced on discovery of a partner's sexual versus emotional infidelity. For example, participants endorsed Nauseated/Repulsed as more likely to follow sexual infidelity and Undesirable/Insecure as more likely to follow emotional infidelity.

Infidelity and the emotional reactions to a partner's infidelity are important phenomena that must be addressed by any purportedly comprehensive theory of romantic relationships, such as an evolutionary psychological theory (Buss, 1994), equity theory (Walster et al., 1978), and an investment model perspective 
(Rusbult, 1980). In addition, the sex differences and infidelity type differences identified in this research should be addressed by any theory of romantic relationships. Thus, a clear direction for future work is to situate these findings within a comprehensive theory of intimate relationship processes and functioning.

Manuscript received 28 August 1999

Revised manuscript received 21 December 1999

\section{REFERENCES}

Betzig, L. (1989). Causes of conjugal dissolution: A cross-cultural study. Current Anthropology, 30, 654-676.

Brown, D.E. (1991). Human universals. New York: McGraw-Hill.

Bryson, J.B. (1991). Modes of response to jealousy-evoking situations. In P. Salovey (Ed.), The psychology of jealousy and envy (pp. 178-207). New York: Guilford Press.

Buss, D.M. (1994). The evolution of desire. New York: Basic Books.

Buss, D.M., \& Craik, K.H. (1983). The act frequency approach to personality. Psychological Review, 90, 105-126.

Buss, D.M., Larsen, R.J., Westen, D., \& Semmelroth, J. (1992). Sex differences in jealousy: Evolution, physiology, and psychology. Psychological Science, 3, 251-255.

Buss, D.M., \& Shackelford, T.K. (1997). From vigilance to violence: Mate retention tactics in married couples. Journal of Personality and Social Psychology, 72, 346-361.

Buss, D.M., Shackelford, T.K., Kirkpatrick, L.A., Choe, J., Lim, H.K., Hasegawa, M., Hasegawa, T., \& Bennett, K. (1999). Jealousy and the nature of beliefs about infidelity: Tests of competing hypotheses about sex differences in the United States, Korea, and Japan. Personal Relationships, 6, 125-150.

Buunk, B.P., Angleitner, A., Oubaid, V., \& Buss, D.M. (1996). Sex differences in jealousy in evolutionary and cultural perspective: Tests from the Netherlands, Germany, and the United States. Psychological Science, 7, 359-363.

Cohen, J. (1988). Statistical power analysis for the behavioral sciences (2nd ed.). Hillsdale, NJ: Erlbaum.

Daly, M., \& Wilson, M. (1988). Homicide. Hawthorne, NY: Aldine de Gruyter.

Daly, M., Wilson, M., \& Weghorst, S.J. (1982). Male sexual jealousy. Ethology and Sociobiology, 3, $11-27$.

DeSteno, D.A., \& Salovey P. (1996). Evolutionary origins of sex differences in jealousy: Questioning the "fitness" of the model. Psychological Science, 7, 367-372.

de Weerth, C., \& Kalma, A.P. (1993). Female aggression as a response to sexual jealousy: A sex role reversal? Aggressive Behavior, 19, 265-279.

Epstein, E., \& Guttman, R. (1984). Mate selection in man: Evidence, theory, and outcome. Social Biology, 31, 243-278.

Geary, D.C., Rumsey, M., Bow-Thomas, C.C., \& Hoard, M.K. (1995). Sexual jealousy as a facultative trait: Evidence from the pattern of sex differences in adults from China and the United States. Ethology and Sociobiology, 16, 355-383.

Hite, S. (1987). Women and love. New York: Knopf.

Hupka, R.B., \& Bank, A.L. (1996). Sex differences in jealousy: Evolution or social construction? Cross-Cultural Research, 30, 24-59.

Kinsey, A.C., Pomeroy, W.B., \& Martin, C.E. (1948). Sexual behavior in the human male. Philadelphia, PA: W.B. Saunders. 
Kinsey, A.C., Pomeroy, W.B., Martin, C.E., \& Gebhard, P.H. (1953). Sexual behavior in the human female. Philadelphia, PA: W.B. Saunders.

Rusbult, C.E. (1980). Commitment and satisfaction in romantic associations: A test of the investment model. Journal of Experimental Social Psychology, 16, 172-186.

Russell, J.A. (1980). A circumplex mode of affect. Journal of Personality and Social Psychology, 39, 1161-1178.

Salovey, P. (Ed.) (1991). The psychology of jealousy and envy. New York: Guilford Press.

Sharpsteen, D.J. (1993). Romantic jealousy as an emotion concept: A prototype analysis. Journal of Social and Personal Relationships, 10, 69-82.

Sharpsteen, D.J., \& Kirkpatrick, L.A. (1997). Romantic jealousy and adult romantic attachment. Journal of Personality and Social Psychology, 72, 627-640.

Vandenberg, S. (1972). Assortative mating, or who married whom? Behavior Genetics, 2, 127-158.

Walster, E., Walster, G.W., \& Berscheid, E. (1978). Equity. Boston: Allyn \& Bacon.

White, G.L., \& Mullen, P.E. (1989). Jealousy. New York: Guilford Press.

Wiederman, M.W., \& Allgeier, E.R. (1993). Gender differences in sexual jealousy: Adaptionist or social learning explanation? Ethology and Sociobiology, 14, 115-140.

Wilson, M., \& Daly, M. (1992). The man who mistook his wife for chattel. In J. Barkow, L. Cosmides, \& J. Tooby (Eds), The adapted mind (pp. 289-322). New York: Oxford University Press.

Zammuner, V.L. (1995). Naõve theories of emotional experience: Jealousy. In J.L. Russell, J. Fernandez-Dols, A.S.R. Manstead, \& J.C. Wellencamp (Eds), Everyday conceptions of emotion (pp. 434-455). Dordrecht: Kluwer.

Zammuner, V.L., \& Fischer, A.H. (1995). The social regulation of emotions in jealousy situations: A comparison between Italy and the Netherlands. Journal of Cross-Cultural Psychology, 26, 189208.

Zammuner, V.L., \& Frijda, N.H. (1994). Felt and communicated emotions: sadness and jealousy. Cognition and Emotion, 8, 37-53. 